\title{
UNA LECTURA MEDIEVAL DEL INTELECTO ACTIVO DE ARISTÓTELES
}

\author{
Pedro Roche Arnas \\ Universidad de Alcalá
}

\begin{abstract}
RESUMEN
Los numerosos interrogantes planteados por el texto sobre el Intelecto Activo en el De Anima de Aristóteles lo convirtieron en un problema central del pensamiento árabe y cristiano. La interpretación de Avempace, cuyo Entendimiento Agente sintetiza los caracteres del Motor Inmóvil aristotélico y del Nous de Plotino, de Dios en definitiva, supone una respuesta de indudable originalidad.
\end{abstract}

Palabras clave: Aristóteles, ententendimiento agente, Avempace, Plotino

\section{ABSTRACT}

The plurality of issues brought up by the text concerning the Active Intellect in the Aristotle's $D e$ Anima made that text to turn into a primary question in the Arab and Christian thought. According to Avempace's interpretation of it, the Agent Intellect summarizes the traits and notes of Aristotle's Motionless Motor and Plotinus' Nous, i. e. of God in short, which no doubt amounts to an original view of the point in question.

Key words: Aristotle, Active Intellect, Avempace, Plotinus

En el alma, según Aristóteles, «existe un intelecto que es capaz de llegar a ser todas las cosas» ${ }^{1}$. Es el intelecto pasivo, potencial, que se identifica con sus objetos y análogo a la materia que en potencia es todas las cosas. Y junto al intelecto pasivo el intelecto activo «capaz de hacerlas todas», semejante al principio causal activo, la causa eficiente que existe en todo proceso, sea natural o técnico, dado que «lo que es acto se genera siempre de lo que es en potencia por la acción de algo que es en acto» ${ }^{2}$. Intelecto activo que es y actúa a modo y semejanza de la luz, porque también ella hace de los colores en potencia colores en acto. Y sin el intelecto activo ningún pensamiento, ningún conocimiento es posible. Frente al carácter potencial, receptivo, pasivo, perecedero y corruptible del intelecto pasivo, Aristóteles señala que el intelecto activo es «separable, sin mezcla e impasible... acto por su propia entidad... Una vez separado... únicamente esto es inmortal y eterno» ${ }^{3}$. $430 \mathrm{a} 15$.

1 Aristóteles, Acerca del Alma, Intr., trad. y notas de Tomás Calvo, Biblioteca Clásica Gredos, Madrid, 1978,

2 Aristóteles, Metafísica, Intr., trad. y notas de Tomás Calvo, Biblioteca Clásica Gredos, Madrid, 1994, $1049 \mathrm{~b} 25$.

3 Aristóteles, Acerca del Alma, 430a 20. 
Son numerosos los interrogantes planteados por el texto aristotélico. ¿Se identifica el intelecto activo con Dios? ' $¿$ Es inmortal nuestra alma? Si el intelecto activo sobrevive al compuesto, ¿es único para todos o individual? Interrogantes con implicaciones fundamentales de carácter antropológico, metafísico y teológico que convirtieron el texto del De Anima en eje central del pensamiento posterior a Aristóteles, y, en especial, de la filosofía árabe y cristiana ${ }^{4}$. La interpretación de Avempace supone una respuesta de indudable originalidad dentro de este contexto.

El inteligible, las formas espirituales universales ${ }^{5}$ no son forma de la materia «ni forma espiritual de un cuerpo con la cual éste existe, como lo son las imágenes de la fantasía. Antes bien los inteligibles son formas que tienen por materia a las formas espirituales intermedias, o sea, a las imágenes de la fantasía» ${ }^{6}$. El inteligible no se reduce a la imagen de la fantasía, pero se encuentra potencialmente en las formas imaginativas, y resulta y viene a existir en la mente a partir de las mismas. ¿Cómo tiene lugar este proceso?

$\mathrm{El}$ hombre adquiere las formas. inteligibles mediante las que conoce los predicados necesarios y esenciales de los seres, en lo que consiste la verdad, por la acción del entendimiento agente sobre las formas espirituales intermedias de la fantasía ${ }^{7}$. «Es el entendimiento (agente) quien hace los universales: tan pronto como él ilumina a una naturaleza, ya puede ser vista, con esa luz, su propia universalidad y también su predicado necesario. Aseméjase, por eso, al que ve con sus propios ojos en medio de la claridad de la luz, mientras que la privación o falta del entendimiento se parece al que ve en medio de la oscuridad... El predicado esencial universal tan sólo es el entendimiento quien lo encuentra, puesto que por los sentidos no conocemos de ese universal más que unos pocos individuos singulares... $\mathrm{y}$, sin embargo, con ese universal podemos juzgar de todo lo que ha existido y existirá, con el mismo acierto que si lo contemplásemos con nuestros propios ojos» ${ }^{8}$.

4 Ramón Guerrero, R., «En el centenario de E. Gilson: Las fuentes árabes del agustinismo avicenizante y el Perì Nố de Alejandro de Afrodisia. Estado de la cuestión», Anales del Seminario de Historia de la Filosofía, $\mathrm{n}^{\circ}$ IV, Ed. Univers. Complutense, Madrid 1984, p. 84: «Muchas han sido las tentativas que se han encaminado a esclarecer tal cuestión a lo largo de los siglos. Se podría afirmar que, desde la muerte de Aristóteles hasta fines de la Edad Media, ningún pensador que haya conocido el De Anima directa o indirectamente, ha dejado de plantearse este problema con la intención de resolverlo, desde autores de fuste hasta personajes anónimos.

También los árabes se vieron inmersos en esta tendencia común al pensamiento postaristotélico. Desde el primer filósofo del mundo islámico hasta su último representante hay un despliegue de obras que tiene como objeto dilucidar el asunto, con lo que contribuyen a ampliar el campo de investigación y de reflexión abierto por Aristóteles».

5 Avempace denomina «formas espirituales» a lo que los escolásticos, siguiendo a Aristóteles, denominaron intentiones o species, tanto impresas como expresas, es decir, a las representaciones del objeto conocido. Con el calificativo de espiritual quiere contraponer estas representaciones cognoscitivas a las formas propiamente dichas que constituyen con la materia prima los cuerpos físicos. Establece una jerarquía de las formas según su mayor o menor grado de inmaterialidad. En el grado tercero de la jerarquía, tras las inteligencias separadas y los entendimientos agente y emanado o adquirido, coloca Avempace las formas inteligibles materiales, es decir, extraídas de la materia por el entendimiento agente a partir de las representaciones de los sentidos internos. El Régimen del Solitario. Avempace, Intr., trad. y notas de Joaquín Lomba, Madrid, 1997, Ed. Trotta, p. 112.

6 Avempace, Tratado sobre la unión del Intelecto con el Hombre, Intr., trad. y notas de Miguel Asín Palacios, Al-Andalus, VII, 1942, p.30.

7 Avempace, al igual que Aristóteles y con el antecedente inmediato de al-Farabi, recurre a la metáfora de la luz, platónica en su origen. El entendimiento agente es respecto de los inteligibles lo que la luz física es respecto de las formas sensibles. Del mismo modo que la forma impresa o grabada en el ojo constituye la visión, la intelección del hombre consiste en la impresión en el entendimiento en potencia de la forma espiritual universal o inteligible. Y de la misma manera que la forma impresa grabada en el ojo, en lo que consiste la visión, existe por la luz, porque el ser y la sustancia de la forma en la luz consiste, al ser la luz la que la hace existir en acto, el inteligible en acto, en lo que consiste el entendimiento en acto o intelección, viene a ser algo real en el entendimiento en potencia por virtud del entendimiento agente. «Así, pues, se ha el entendimiento en acto respecto del entendimiento agente: una sola y la misma es la relación entre ambos, en uno y otro caso: lo que la luz física es respecto de la forma sensible, eso es también el entendimiento agente respecto de los inteligibles, pues en cierto aspecto y por analogía es también luz». Avempace, Ibid, p.40.

8 Avempace, Carta de Adiós, Intr., trad. y notas de Miguel Asín Palacios, Al-Andalus, VIII, 1943, p.79. 
Pero la percepción o conocimiento del hombre respecto de los inteligibles, y del entendimiento agente en definitiva, tiene diferentes grados de intensidad, calidad y perfección. Señala Avempace de forma reiterada que es un proceso semejante a una ascensión con diferentes grados que tienen como referencia su mayor o menor alejamiento de la materia.

«Es el primero el grado vulgar, que es el grado natural. Para los que lo ocupan, el inteligible está ligado tan sólo con las formas materiales, y no los conocen sino con ellas, de ellas, desde ellas y por ellas» ${ }^{9}$. El conocimiento está ligado a los datos sensibles materiales, reducido su horizonte a lo que se percibe, recuerda o imagina. «El vulgo ve del inteligible la imagen de su imagen, como cuando el sol lanza su imagen sobre el agua y aquélla se refleja en un espejo» ${ }^{10} \mathrm{y}$, respecto del entendimiento agente, «lo verá tal y como ve la luz que se refleja de las superficies de los cuerpos de colores, y se guiará por él en cierto modo, como se guía por el sol el que camina en la sombra» ${ }^{11}$. Utilizando la alegoría de la caverna de Platón, afirma «que el estado del vulgo, respecto de los inteligibles, se parece mucho a la condición de quienes se sirven del sentido de la vista dentro de una cueva: como sobre ellos no brilla el sol dentro de ella, no lo ven, sino que ven todos los colores en la sombra... así también, para el vulgo, carece de realidad aquel entendimiento y ni de su existencia se dan cuenta ${ }^{12}$. Continuando con los ejemplos de raíz platónica, podríamos señalar que el horizonte de conocimiento del vulgo, en la escala platónica del símil de la línea ${ }^{13}$, que Avempace no utiliza, sería el que corresponde a la creencia, que tan solo genera opinión y no ciencia.

El grado segundo «es la intuición especulativa o teórica, que está todavía en la cima del grado natural» ${ }^{14}$. Mediante la ciencia el hombre capta lo universal, necesario e inmutable. Supone este nivel, por lo tanto, un alejamiento de lo individual, de lo múltiple y de lo cambiante, elementos constitutivos del conocimiento vulgar del primer nivel. A diferencia del conocimiento vulgar que «mira primeramente a los objetos, y en segundo lugar al inteligible por razón de los objetos, los teóricos de la física miran primero al inteligible, y a los objetos en segundo lugar y por razón del inteligible analógicamente; y por eso miran primero al inteligible si bien van juntas con éste las formas materiales. Por eso, las proposiciones empleadas en las ciencias contienen, todas ellas, sujetos y predicados singulares y concretos, y (sin embargo) son todas ellas universales» ${ }^{15}$. Existen, como vemos, diferencias profundas entre el conocimiento vulgar y el conocimiento científico.

Avempace, aunque señala que el científico viene a estar ya en otro rango que lo diferencia por completo del vulgo, afirma, sin embargo, que participa todavía de la condición del vulgo aunque sea de un modo relativo ${ }^{16}$. La ciencia es la cima que el hombre puede alcanzar con sus solas fuerzas naturales, $y$ aunque existen diferencias profundas entre el valle y la cima, entre el conocimiento vulgar y el conocimiento científico, ambos comparten el marco de lo natural. Tanto el conocimiento vulgar como el de los hombres dados a la especulación, el de los que filosofan, utilizan el mismo procedimiento o camino, el procedimiento abstractivo, «el método más apto y cómodo porque está dentro de lo natural, y por ello es común a los filósofos y

9 Avempace, Tratado sobre la unión del Intelecto con el Hombre, p. 38.

10 Avempace, Ibid., p.39.

11 Avempace, Ibid., p.43.

12 Avempace, Ibid., p.41.

13 Platón, República, VI, 509d-511e.

14 Avempace, Ibid, p.41.

15 Avempace, Ibid, p. 39.

16 A. Altmann afirma que Avempace insiste en que no hay, en último término, diferencia esencial entre el nivel del vulgo y el del científico especulativo, dado que en ambos niveles la unión con los inteligibles puros del entendimiento agente no es directa, sino que se realiza a través de la mediación de las formas materiales y espirituales. Citando a Averroes, nota 29, p. 82, señala que, según él, Avempace establece la existencia de tan sólo dos clases de hombres: los afortunados y el vulgo. «Ibn Bâjja on Man's Ultimate Felicity», Studies in Religious Philosophy and Mysticism, London, 1969, p. 82. 
al vulgo» ${ }^{17}$. La condición respecto de los inteligibles de quienes cultivan la ciencia matemática o física «es la misma del vulgo, ya que su unión con los inteligibles se realiza, en ellos y en el vulgo, de un solo y el mismo modo y conforme a igual norma... mediante cosas que hacen las veces de los individuos singulares, exactamente igual que sucede con los conceptos obtenidos por la potencia imaginativa y el sentido común... Esto, pues, equivale a decir que lo material no se une con el inteligible, sino mediante las formas espirituales» ${ }^{18}$.

Esta es la razón por la que los inteligibles de los científicos y de quienes filosofan, tanto si lo hacen sobre cosas prácticas como teóricas, son imperfectos. Al unirse con el inteligible mediante las formas espirituales de la imaginación bajo la acción del entendimiento agente, el inteligible está lastrado por lo material. Mediante la ciencia el hombre capta lo universal, inmutable y necesario, pero el hecho de que los conceptos o ideas científicas procedan por abstracción racional del mundo de los individuos materiales, les hace no estar totalmente exentos del mundo de la materia. De aquí que quien alcanza este grado especulativo o teórico «ve el inteligible, pero a través de un medio, tal como aparece el sol reflejado en el agua, puesto que lo que en el agua se ve es su imagen y no el sol mismo» ${ }^{19}$.

La unión con los inteligibles por el método natural, es decir, mediante el proceso de abstracción a partir de los datos sensibles bajo la acción del entendimiento agente, constituye el término medio de la ascensión, el conocimiento científico. El hombre, sin embargo, puede dirigir la mirada al inteligible en sí mismo, más allá del conocimiento especulativo científico o filosófico en el que el inteligible dice relación a las cosas singulares o a las formas imaginativas de éstas. Ya no se trata del conocimiento de un determinado inteligible, sino, a través de este inteligible, del conocimiento del inteligible en tanto que inteligible: «el que cultiva la ciencia física elévase luego a otro grado más alto y especula sobre los inteligibles, no en cuanto que son inteligibles con la denominación de materiales ni de espirituales, sino en cuanto que los inteligibles son uno de los entes del mundo» ${ }^{20}$. Desmaterializados por un supremo grado de abstracción, es decir, despojados de las relaciones a las cosas y a las imágenes de la fantasía, perderán la multiplicidad y diversidad que lastraban en el ámbito especulativo de la ciencia estos inteligibles. Será una idea sin idea, una forma simple y eterna. Los inteligibles purificados de todo contacto con la materia, «han logrado un nuevo status ontológico, llegando a ser uno de los entes del mundo... por encima de los géneros y especies» ${ }^{21}$. Y el conocimiento de estos inteligibles puros en el tercer grado de la ascensión constituye el entendimiento adquirido.

¿Qué supone alcanzar el entendimiento adquirido? La unión con el entendimiento agente. En los inteligibles puros y en el entendimiento adquirido «que no es otra cosa que el entendimiento agente operando en el hombre sin apoyo o estorbo de la materias ${ }^{22}$, conoce el hombre el entendimiento agente que ha tomado posesión plena del intelecto humano: el inteligible ya no será el medio en el que conocemos analógicamente los objetos, siendo un término medio para la relación del hombre con las cosas de las que abstrae el inteligible, sino el medio mediante el que el hombre se une con el entendimiento agente. ¿Por qué? Al carecer el entendi-

17 Avempace, Ibid, p. 36.

18 Avempace, Ibid., p. 35.

19 Avempace, Ibid., p.39.

20 Avempace, $I$ bid, p.36.

21 Altmann, A., Op. cit., p. 106. En otro momento, p. 78, afirma Altmann que «hay una vuelta clara a la doctrina platónica de las Ideas, aunque de una forma modificada. De una forma que recuerda la admisión de las Ideas platónicas por Boecio sobre y por encima de las especies y los géneros de Aristóteles, Avempace establece-la diferencia entre los inteligibles materiales, las especies y géneros, que tienen una relación universal con los datos individuales de los sentidos, y los inteligibles puros en los que se ha borrado incluso la relación universal con los objetos de la percepción sensible y de la imaginación».

22 Altmann, A., Op. cit., p. 101 
miento de forma espiritual que le sirva de objeto, el inteligible del entendimiento será el propio entendimiento. El entendimiento, el inteligible y la intelección se identifican. El conocimiento del inteligible puro supone el conocimiento del intelecto puro. Para la visión de los afortunados «ya no hay nada que se les asemeje en la visión física, puesto que vienen a ser la misma cosa entendida. Si fuera posible comparar este estado con el de los que físicamente ven y éstos se convirtieran en luz, tal vendría a ser la condición de los afortunados» ${ }^{23}$.

Conocemos ya los efectos de la acción del entendimiento agente sobre el hombre ${ }^{24}$. ¿Cuál es la naturaleza de este entendimiento?

La primera afirmación que podemos mantener es la unicidad del entendimiento agente y la unidad en el entendimiento agente de todos los hombres que alcanzan el grado del entendimiento adquirido.

Como hemos señalado, los inteligibles de los científicos y de quienes filosofan están lastrados por la materia. Y dado que el inteligible existente en la mente es, por su referencia a lo imaginativo y a lo sensible de lo que procede, algo relativo a una multiplicidad de individuos diferentes en la mente de cada hombre, el entendimiento que capta este inteligible a partir de las imágenes del la fantasía es material o hylico «y por eso sus entendimientos son muchos en número, y de ahí que se crea que el entendimiento es múltiple» ${ }^{25}$. El alma racional es numéricamente múltiple porque entiende los inteligibles materiales que son numéricamente múltiples.

Frente a la multiplicidad y materialidad del alma racional, de los entendimientos en potencia o material y en acto, el entendimiento, en su grado último, es numéricamente uno en todos los hombres. El grado tercero de la ascensión suponía alcanzar los inteligibles puros, el entendimiento adquirido, de donde se ha borrado incluso la relación universal con los objetos de la percepción de los sentidos y de la imaginación, y en ellos y en él al mismo entendimiento agente. Entendimiento adquirido que es «uno o simple bajo todo aspecto y está en el summum de la lejanía de la materia... El, es, pues, siempre uno solo y simple y se mantiene en uno solo y el mismo estado» ${ }^{26}$. «Este grado tercero del entendimiento - y no más que él- es uno solo y el mismo, bajo todo aspecto, imperecedero e incorruptible» 27 .

Y si existe un solo entendimiento numéricamente uno, los individuos singulares que posean tal entendimiento serán todos ellos uno solo con unidad numérica, del mismo modo que son un solo motor las diferentes capas de cera, de pez o de resina que recubren una piedra imán. «Por él tan sólo, son numéricamente uno y el mismo los anteriores y posteriores en el tiempos ${ }^{28}$. Por otro lado, hemos hablado de los inteligibles puros. En realidad deberíamos hablar del inteligible puro. En el grado de entendimiento adquirido «el inteligible es numéricamente uno cuando es recibido como inteligible puro compartido con el entendimiento agente» ${ }^{29}$. Y

\section{Avempace, $l$ bid, p.41.}

24 Lomba, J., El Régimen del solitario. Avempace, Intr., trad. y notas de Joaquín Lomba, Madrid, 1997, Ed. Trotta, p. 54: «Y este Intelecto Agente tiene con respecto al hombre una triple función: en primer lugar, iluminar al intelecto en potencia o material del hombre para hacerlo pasar a intelecto en acto, proporcionándole así el conocimiento de los inteligibles universales y de las esencias propias de la ciencia que se abstraen de lo material... En segundo lugar, y ello supone un paso más adelante hacia la máxima espiritualidad, puede también comunicarle los inteligibles puros y totalmente espirituales que tiene en su interior, convirtiéndolo entonces en intelecto adquirido. Y por último, en tercer lugar, y ésta es la cima de la espiritualidad y perfección, puede hacer que el hombre se una místicamente al intelecto agente y a Dios, cerrándose así el ciclo completo de la espiritualización unificadora y de la adquisición de la sabiduría, más allá de la razón y de la ciencia. Con ello hemos llegado al colmo de la perfección y felicidad humana, a la meta máxima a la que puede aspirar, al fin supremo del hombre».

25 Avempace, Ibid, p. 37

26 Avempace, Carta de Adiós, p. 84.

27 Avempace, Tratado sobre la unión del Intelecto con el Hombre, p. 45.

28 Avempace, Ibid, p. 45.

29 Altmann, A., Op. cit., p. 101. 
la unidad numérica del inteligible implica la unidad de todas las almas en este grado de entendimiento adquirido, supone «la presencia simultánea del entendimiento en todas las almas» $^{30}$. Quien alcanza este grado supremo de intelección «viene a ser también uno solo, con unidad numérica, aunque sea múltiple por razón de los órganos o instrumentos de que se sirve» ${ }^{31}$.

La unión o fusión con los demás afortunados en el entendimiento agente a través de su acción en nosotros como entendimiento adquirido, una vez alcanzado el tercer grado de la ascensión, no es sólo la unión con un ente divino. Es la unión con Dios o, al menos, la unión con una realidad que posee rasgos fundamentales del Dios de Aristóteles ${ }^{32}$. Y no sólo del Dios de Aristóteles sino también, en coherencia con el marco intelectual y el momento histórico que le corresponde vivir, del Nous de Plotino, de la inteligencia plotiniana, una de las tres hipóstasis constitutivas del Ser Uno y Divino.

Avempace atribuye al entendimiento agente rasgos o caracteres propios del Dios de Aristóteles ${ }^{33}$, siguiendo, o creyendo seguir, como veremos, la estela de Alejandro de Afrodisia ${ }^{34}$. Cuando el entendimiento carece de forma espiritual que le sirva de objeto, de materia, es decir, de formas espirituales imaginativas, su inteligible es el mismo entendimiento. Entendimiento e inteligible se identifican, «coinciden inteligencia e inteligible», como señala Aristóteles refiriéndose a Dios $^{35}$. El acto de este entendimiento es su propia sustancia, retorna sobre sí mismo «piensa en sí mismo, y su pensamiento es pensamiento de pensamiento «con palabras de Aristóteles ${ }^{36}$. El conocimiento de la idea sin idea, del inteligible purificado de todo contacto con la materia, es el conocimiento de una forma pura y, dado que lo que se comprende del inteligible es lo que se comprende de ese entendimiento, será el conocimiento del acto puro, de lo que es incorruptible y eterno, de «lo que no se desgasta ni corrompe» ${ }^{37}$. La intuición de la forma pura, de lo que es incorruptible y eterno, del entendimiento agente no es «por tanto, y aquí está la novedad radical del pensamiento de Avempace, un motor más dentro de aquella escala que iba del primer creado hasta el mundo sublunar, como habían creído al-Farabi y Avicena, sino la forma misma del acto intelectual concebida en su momento supremo de eternidad, universalidad, simplicidad y realidad, y un ser así sólo puede ser Dios» ${ }^{38}$.

Avempace, sin embargo, al referirse al Libro sobre las Formas Espirituales cree seguir la doctrina de Aristóteles y Alejandro. Y comparte básicamente, por lo que hemos dicho, esta posición. No es, sin embargo, a Alejandro de Afrodisia, en quien existen también, sin duda, ele-

30 Altmann, A., Op. cit, p. 103.

31 Avempace, Ibid, p. 38.

32 Lomba, J., Op. cit., p. 55, «La duda está en si esa unión con el Intelecto Agente equivale a la unión con Dios. La respuesta puede ser afirmativa a juzgar por lo que se desprende de las mismas palabras de Avempace a lo largo de toda su vida, aunque no llegue a decirlo con toda claridad».

33 Lomba, J., «Tratado sobre el Entendimiento Agente» de Avempace, Memoria-Homenaje a Adolfo Arias Muñoz, Anales del Seminario de Historia de la Filosofía, $\mathrm{N}^{\circ}$ Extra, Madrid, 1996, p. 268: «En este nivel, en su cima, se halla el Intelecto Agente que es el motor de todo cuanto hay. Y en él, se identifican sujeto pensante, objeto pensado y pensamiento; viene a ser la noésis noéseos aristotélica».

34 Avempace, Ibid, p.38: «En este entendimiento, el motor es el mismo móvil. De modo que — según dice Alejandro en su Libro sobre las formas espirituales - retorna sobre si mismo». Sobre la influencia de Alejandro de Afrodisia en los filósofos árabes, tesis por algunos duramente criticada, conviene recordar la afirmación de Rafael Ramón Guerrero: «Hoy se puede afirmar firmemente que las obras de Alejandro referentes al problema planteado por Aristóteles, las que Ilevan por título De Anima y De Intellectu, fueron conocidas por los filósofos árabes, al menos desde al-Farabi, ejerciendo sobre ellos una influencia, si no profunda, sí al menos importante y, a veces, determinante». La recepción del De Anima de Aristóteles: al-Kindi y al-Farabi. C.S.I.C., Madrid, 1992, p: 62.

35 Aristóteles, Metafísica, XII, 7,1072b 18-24.

36 Aristóteles, Ibid, XII, 9, $1074 \mathrm{~b} 34$.

37 Avempace, Ibid, p. 38

38 Cruz Hernández, M., Filosofia Hispano-Musulmana, Asociación Española para el Progreso de las Ciencias, Madrid, 1957, p. 357. 
mentos platonizantes, a quien está textualmente citando al exponer la naturaleza del entendimiento agente. Está parafraseando a Proclo ${ }^{39}$. Es doctrina neoplatónica.

No hay duda sobre el carácter neoplatónico de la ascensión de Avempace: es un proceso cuyo punto de referencia es el mayor o menor alejamiento de la materia y cuya finalidad, la consecución del fin último del hombre, es unirse, fundirse con lo divino. Como neoplatónicas son las imágenes y analogías que utiliza para ilustrar los diferentes momentos de la ascensión: el símil de la oscuridad, la sombra y la luz, la analogía de la caverna de Platón, la imagen del entendimiento agente como sol y luz...Y en especial son netamente neoplatónicos algunos caracteres últimos del entendimiento agente: ¿acaso el entendimiento agente de Avempace que es «uno solo con unidad numérica, y es el motor primero ejemplarmente ${ }^{40}$, «sostén de las cosas todas» ${ }^{41}$, unidad de intelección e inteligible, no es análogo al nous o intelecto plotiniano, unión entre el supremo pensamiento y lo supremo pensado, inteligencia que piensa la totalidad de los inteligibles, fuente del conocimiento y fuente del ser?

Será, sin embargo, la naturaleza de la unión del hombre con el entendimiento agente, cuyo contenido nos remite al concepto de enosis de Plotino y sus sucesores mediante el que designan el último grado de unión mística, la que nos mostrará con mayor claridad, creo, la profunda huella del neoplatonismo en Avempace. Afirma, describiendo los fenómenos psíquicos que acompañan al afortunado en su unión con el entendimiento agente, que «uno de ellos afecta a la fantasía, en la cual nace un algo que es análogo a este entendimiento, es decir, una luz, la cual, cuando enviste a una cosa, hace ver todo lo que no es ella bajo un aspecto inefable o difícil de explicar con palabras. En el alma apetitiva nace, en tal grado, un estado psíquico semejante al temor reverencial parecido en cierto modo al estado de ánimo que sobreviene al ver algo grandioso y bello; ese estado de alma se le llama estupefacción... A esta última (la parte apetitiva racional del alma) le sobreviene también en este grado un estado psíquico que se le parece a la emoción de alegría extremada que siente el que está orgulloso de poseer algo en cuya comparación todas las cosas le son ya despreciables» ${ }^{42}$.

La naturaleza de esta unión es de carácter especulativo, contemplativo, teorético, pero a la vez, es una unión intuitiva y mística, concebida, de acuerdo con la doctrina neoplatónica, como un éxtasis intelectual ${ }^{43}$.. En ella se produce una conmoción total del hombre viéndose profundamente afectadas todas las facultades del alma. Se trata de una mística total e integralmente sûfi y de los Hermanos de la Pureza, como señalan Joaquín Lomba y Kraemer ${ }^{44}$ : Avempace «emplea el mismo término que los sûfies para designar la unión mística con Dios, ittisâl, y dado que esta idea implica una unión ontológica y, además, amorosa, muy bien podría hablarse en

39 Como señala Altmann, el Tratado sobre la Prueba de la existencia de las Formas Espirituales que no tienen Materia, atribuido a Alejandro de Afrodisia, es una versión árabe de las proposiciones 15, 16 y 17 de Los Elementos de Teología de Proclo. La cita de Avempace está tomada de las proposiciones 15 y 16, que afirman que todo aquello que es capaz de volver sobre sí mismo es incorpóreo, espiritual, y tiene una existencia separable del cuerpo. La identidad del motor y del móvil tiene lugar en la proposición 17. Op.cit., p. 96.

40 Avempace, $\mathrm{Ibid}, 38$.

41 Avempace, Carta de Adiós, p. 84.

42 Avempace, Tratado sobre la unión del Intelecto con el Hombre, p. 45.

43 Dos textos de Plotino nos muestran el estado en que se encuentran quienes alcanzan la unión con Dios o el Uno, tras liberarse el hombre de la tiranía de lo corporal, tras elevarse por encima de las percepciones sensibles y ocuparse de la filosofía y de la ciencia y tras alcanzar la unión con el Nous, más allá del pensar discursivo, estadios todos preparatorios para la unión mística con Dios o el Uno: «Allí verá el hombre, como pueden verse en el cielo, a Dios y a sí mismo a la vez: hecho él mismo radiante, lleno de la luz inteligible o, más bien, identificado con esta luz en toda su pureza, sin pesantez ni carga alguna, transfigurado en divinidad, convertido sí, esencialmente en Dios», Enneadas, VI, 9, 9, 768f-769d. «Resulta difícil traducir en palabras semejante visión. Pues, ¿cómo podría el hombre dar cuenta de lo divino cual si fuera una cosa distinta, siendo así que en la visión lo conoció no como distinto de sí sino como idéntico con su propia conciencia?», Enneadas, VI, 9, 10, 769d.

44 Kraemer, J. L., «Ibn Bâjja y Maimónides: sobre la perfección humana», Congreso Internacional sobre las Tres Culturas, Madrid, 1992, p. 245: «Ibn Bâjja empujó los temas de Aristóteles en dirección al sufismo». 
el caso de Avempace de una especie de amor Dei intellectualis, o amor intelectual a Dios en el que el acto amoroso no se desarrollase en el nivel de la unión de los sentimientos y del corazón sino del intelecto» ${ }^{45}$. Unión que, a su vez, es un don y una donación de Dios ${ }^{46}$. Unión que eleva, transfigura y diviniza al hombre ${ }^{47}$.

En síntesis, Avempace parte de un esquema netamente aristotélico. Sin embargo, «todo este mecanismo del conocer sólo constituye una etapa preparatoria de aquello que auténticamente es el conocimiento más alto y más propiamente humano: la unión del hombre con el in-

45 Lomba, J., El Régimen del solitario. Avempace, Intr., trad. y notas de Joaquín Lomba, Madrid, 1997, Ed. Trotta, p. 54.

46 Roche Arnas, $\mathrm{P} .$, «El fin último del hombre según Avempace», Pensamiento Medieval Hispano. Homenaje a Horacio Santiago-Otero, Coord.. José María Soto Rábanos, C.S.I.C., Madrid, 1998, pp. 970-971: «El conocimiento filosófico o científico constituye el grado segundo de una ascensión que puede culminar en la unión con el entendimiento agente, en la sabiduría. Este poder alcanzar la sabiduría, ¿depende de las propias fuerzas y esfuerzo del hombre? Todos los hombres pueden alcanzar el grado de perfección propio de la ciencia especulativa que, no olvidemos, es la cima del método natural aunque tan sólo el término medio de la ascensión. La consecución del grado supremo, de la meta última, ¿depende del hombre o es un don de Dios?

La duda se plantea a causa de un texto de Ibn Tufayl citado por J. Lomba en El Régimen del solitario. Avempace, Madrid, 1997, Ed. Trotta, p. 57, en el que afirma que Avempace centró el fin del hombre y la unión mística en la imaginación, lo que no es cierto como hemos visto, y que redujo la consecución de este fin a las solas fuerzas naturales del hombre.

Avempace afirma reiterada y claramente que esta unión es dada graciosamente por Dios. En el Régimen del Solitario, p. 75, refiriéndose a las cosas que se alcanzan en esta unión con el entendimiento agente, afirma «son dones divinos con los que Dios Altísimo distingue a las criaturas que Él quiere, sin que el hombre tenga en ello participación alguna». Y en el Tratado sobre la Unión del Intelecto con el Hombre, p. 32, indica que «es evidente que este entendimiento, que es numéricamente uno, es don y beneficio de Dios, con el que Este recompensa a aquellos de entre sus siervos que bien le place». Al final de este tratado, a modo de apéndice y escrito de su puño y letra, afirma que «hay en él, sin embargo, algunos indicios de aquella demostración apodíctica, suficientes para que, si el texto se explica como debe explicarse y llega a hacerse comprender la idea que expresa, aparezca entonces claro que la cosa no puede ser conocida mediante las ciencias con ella enlazadas en grado, sino que quien concibe esa idea, después de haberla comprendido, vendrá a estar en un grado en el cual su propia alma verá, a diferencia de todas sus anteriores opiniones, otras cosas que ya no son materiales, sino demasiado sublimes para que puedan referirse a la vida física, puesto que más bien son ya estados anímicos propios de los afortunados, exentos de la composición que caracteriza a la vida natural y dignos por eso de que se les diga estados divinos, que dios, ipoderoso y grande!, da graciosamente a aquellos de sus siervos que bien le place». La unión con el entendimiento agente, no puede lograrse sólo con el estudio de las ciencias especulativas. Supone algo superior a la vida natural, al método natural y a las fuerzas o capacidades puramente naturales del hombre. Supone un don y una donación de Dios. Si en Aristóteles el hombre logra su fin último mediante el pensamiento especulativo, en Avempace éste será el fundamento más seguro para conducir al alma hacia su fin último, pero su consecución será, en último término, un don de Dios.

De aquí la plena validez de las afirmaciones de Asín Palacios, Tratado de Avempace sobre la unión del Intelecto con el Hombre, Intr.., trad. y notas de Miguel Asín Palacios, Al-Andalus, VII, 1942, p. 4, al señalar «que la unión del hombre con el intelecto agente, es decir, la intelección pura de Aristóteles, aunque condicionada necesariamente por el previo estudio progresivo de todas las ciencias especulativas y por la adquisición de las virtudes morales, es en última instancia un don gratuito de Dios. Hay que rectificar por lo tanto el juicio que formuló Munk sobre Avempace, al decir que imprimió a la filosofía árabe en España un movimiento totalmente opuesto a las tendencias místicas de los sufies, por considerar la ciencia especulativa como el solo medio capaz de conducir al hombre a su fin último».

47 Avempace considera que la unión del hombre con el Entendimiento Agente significa el más alto grado de perfección humana, el fin de todo el esfuerzo racional del hombre, la sabiduría o posesión del verdadero y supremo saber, de naturaleza tal que eleva y transfigura al hombre. «Y cuando llega al fin último, comprendiendo racionalmente las inteligencias simples y las sustancias que se mencionan en la Metafísica, en el libro Sobre el Alma y en el libro Sobre el Sentido y lo Sensible, entonces se hace una de aquellas inteligencias y en verdad (se le puede aplicar en ese momento el calificativo) de únicamente divino, desapareciendo de él las cualidades sensibles caducas así como las excelsas espirituales. Sólo le cuadrará entonces el (nombre) de simplemente divino». Pedro Roche Arnas, «Qué es filosofía para Avempace», Was ist Philosophie im Mittelalter?, Akten des X. Internationalen Kongresses für mittelalterliche Philosophie der Société Internationale pour l'Etude de la Philosophie Médiévale, Berlín-New York, 1998, Walter de Gruyter, p. 858. 
telecto agente» ${ }^{48}$. Su concepción más profunda es claramente neoplatónica. Avempace sintetiza así, de una parte, la dirección místico-especulativa de Ibn-Masarra, que desarrolla el neoplatonismo introducido en España por los Mutazilíes, y, de otra, el aristotelismo neoplatonizado de al-Farabi. Siendo esto así, su lectura del entendimiento agente debía traducir esta síntesis y la traduce al poseer éste los rasgos del motor inmóvil de Aristóteles y del nous de Plotino, al ser el «motor primero ejemplarmente» ${ }^{49}$, ese intelecto divino que "permaneciendo siempre uno en sí, ilumina por el desbordamiento de sus rayos las tan variadas formas que el hombre puede alcanzar por su conocimiento ${ }^{50}$.

\section{Pedro Roche Arnas Antiguo Colegio de Málaga C/ Colegios, 2}

28801 Alcalá de Henares (Madrid) E-mail: pedro.roche@uah.es 